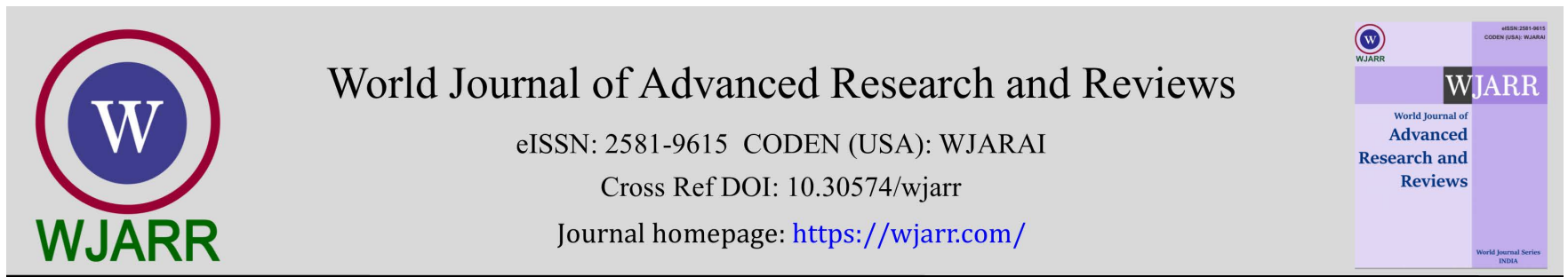

(RESEARCH ARTiCle)

Check for updates

\title{
Prevalence of Hepatitis B viral infection amongst pregnant women in rural community in Southern Nigeria
}

\author{
Orluwene CG ${ }^{1}$, Eli S ${ }^{2,}{ }^{*}$, Okagua $\mathrm{KE}^{3}{ }^{3}$, Owhonda G ${ }^{4}$, Tee GP ${ }^{5}$, Nnoka V ${ }^{6}$ and Emeghara GI 5 \\ 1 Provost College of Medical Sciences, Rivers State University/Department of Chemical Pathology, University of Port \\ Harcourt Teaching Hospital. \\ 2 Mother, Baby and Adolescent Care Global Foundation. \\ ${ }^{3}$ Department of Obstetrics and Gynae cology, Rivers State University Teaching Hospital. \\ ${ }^{4}$ Department of Community Medicine, Rivers State Universty. \\ 5 Department of Human Physiology, Rivers State University. \\ ${ }^{6}$ Department of Pharmacology, Rivers State University.
}

World Journal of Advanced Research and Reviews, 2021, 12(03), 393-397

Publication history: Received on 06November 2021; revised on 19December 2021; accepted on 21 December 2021

Article DOI: https://doi.org/10.30574/wjarr.2021.12.3.0674

\begin{abstract}
Background: Hepatitis B Viral (HBV) infection is a potentially fatal infection of public health importance globally. Pregnant women and their unborn children are at risk of this infection due to its mode of transmission especially when in contact with infected body fluids and from mother to child transmission respectively. The prevalence of HBV infection in Nigeria is $13.6 \%$.
\end{abstract}

Aim: To determine the prevalence of HBV infection amongst pregnant women in rural community in southern Nigeria.

Methods: This was a retrospective cross sectional study of pregnant women at Ogoni Primary Health Centers and General Hospitals in Southern Nigeria carried over a 4-month period. Serological test results for Hepatitis B surface antigen (HBsAg) of subjects were retrieved from the laboratories. Permission was gotten from Director of Public Health Rivers State Ministry of Health. The information gotten was analyzed using independent $t$ test, chi square and fisher exact tests. Significance level was set at 0.05 .

Result: One hundred and eighty-five pregnant women were recruited for the study. The mean age of the antenatal clinic attendees was $28 \pm 2$ years, the mean gestational age at booking was 25 weeks and the mean parity was 2 . Majority had secondary level of education represented by 122 (66\%). Fifteen (8.1\%) of the pregnant women were positive for Hepatitis B surface antigen.

Conclusion: The prevalence of HBV infection was $8.1 \%$ in Ogoni southern Nigeria. This is worisome, hence preventive measures including HBV vaccines should be made available to the populace.

Keywords: Prevalence; HBV; Infection; Southern; Nigeria

\section{Introduction}

Hepatitis B Viral (HBV) infection is a potentially fatal infection of public health importance globally. Pregnant women and their unborn children are at risk of this infection due to its mode of transmission especially when in contact with

\footnotetext{
${ }^{*}$ Corresponding author: Eli S

Mother, Baby and Adolescent Care Global Foundation.
}

Copyright ( 12021 Author(s) retain the copyright of this article. This article is published under the terms of the Creative Commons Attribution Liscense 4.0 
infected body fluids and from mother to child transmission respectively. The prevalence of HBV infection in Nigeria is $13.6 \%$ [1]. Chronic liver-disease is a major cause of chronic infection with HBV which remains endemic in many countries of the world inspite of worldwide implementation of HBV vaccination [2]. Even though, the World Health Assembly has adopted the goal of eliminating the HBV as a major public health threat by 2030 , targeting $90 \%$ reduction of new infection and $65 \%$ of mortality [2].

There are myriad of ways by which HBV infections could be transmitted examples of which are contacted with infected body fluids which also includes transmission of infected blood with the HBV infection [2-4]. In addition, other means by which the HBV infection is transmitted intravenous blood users, through sexual intercourse and from mother to child [4-6]. Of much concern to the obstetrician and gynaecologist is the mother to child transmission of HBV infection also known as vertical transmission [7-10]. Management of pregnant women infected with HBV infection is multidisciplinary involving the internist, paediatrician, haematologist, counselors just to mention a few [8-10].

The global prevalence of HBV infection is $3.9 \%$, with an estimate of 325 million people worldwide live with the virus, with 1.5 million new cases annually as reported by the World Health Organization (WHO) [1,8-10]. African and SouthEast Asian countries have greatest burden of HBV infections, with majority of this countries with prevalence rates greater than 8\% [8]. Examples of countries with high prevalence of HBV infection as documented by the WHO and the CDC includes Bangladesh, Georgia, Mauritania, Namibia, Pakistan, Nigeria [11].The prevalence of HBV infection in Nigeria is $13.6 \%$ [8]. It is however of great concern due to the fact that majority of persons living with HBV infections are resident in Sub-Sahara Africa and Asia [7,8]. The prevalence rate of HBV infection is low in developed countries of the world. Lim JK et al reported a prevalence of $4.6 \%$ in the United States of America with 1 in 7 Americans infected with HBV [2].

Researchers have shown that there is an associated high mortality rate amongst those infected with HBV infections $[9,10]$. This is because evidence from studies done have revealed that HBV infection primarily affects the liver and could lead to liver related mortalities if not properly treated [2-4,11-13]. The worrisome high prevalence of HBV infection in Nigeria and providing remedy on how to curtail this infection is the justification for this study.

\section{Aim}

To determine the prevalence of HBV infection amongst pregnant women in rural community in southern Nigeria.

\section{Methods}

This was retrospective cross-sectional studyof pregnant women at Ogoni between $1^{\text {st }}$ November, 2019 to $28^{\text {th }}$ February, 2020 (3 Primary Health Centers and 2 General Hospitals) in southern Nigeria.Laboratory records of serological testing on all patients for HBV performed at the health centers and general hospital.

Hepatitis B surface antigens (HBSAg) serological test results for pregnant women were extracted from laboratory records of participants were recorded. The age distribution of the pregnant women were noted. Furthermore, other information from participantswhich included their parity, educational status and gestational ages were also noted.

Serology for HBSAg was performed using HBSAG rapid test strip (Hangalious Biotest Biotech Co Ltd, China and Citrus Diagnostics Inc.Canada). This was done in accordance to manufacturer's instructions. There were no direct contact with the patients. The information obtained wasanalysedusing descriptive statistics in the form of standard deviation, frequency and proportion was performed using independent, chi square test and fishers exact tests as appropriate. Significance level was set at 0.05 .

\subsection{Sample size estimation}

The sample size of 185 was calculated using the Kish Leslie formula for cross-sectional studies calculated, based on 13.6 $\%$ (rounded up to 14\%) prevalence of HBV infection in Nigeria by a study done by Musa et al ${ }^{1}$ at confidence level of $95 \%$.

$$
\mathrm{n}=\mathrm{Z}^{2} \mathrm{Pq} / \mathrm{d}^{2}
$$

Where

$\mathrm{n}$ is the desired sample size 
$\mathrm{Z}$ is the standard normal deviate usually set at 1.96 , which corresponds to the confidence interval

$\mathrm{P}$ is the prevalence of $\mathrm{HBV}$ infection which in this case is $14 \%$

$\mathrm{q}$ is complementary proportion equivalent to one (1), that is $1-0.14 \%$ equal to $0.86 \%$

$\mathrm{d}$ is the degree of accuracy desired which is $5.0 \%(0.05 \%)$

$$
\mathrm{n}=1.96^{2} \times 14(1-0.14) / 0.05^{2}
$$

$=185$

\subsection{Study Population}

This is a distinct ethnic nationality within the Federal Republic of Nigeria. The population of Ogoni is over 1 million with capital in Bori occupying $1000 \mathrm{~km}^{2}$.The languages of the Ogoni people are Khana, Gokana, Eleme, Tae; distinct languagewithin the Benue-Congo branch of African languages. The religion of the Ogonis are traditional beliefs and Christianity. ${ }^{11}$

\section{Results}

One hundred and eighty-five pregnant women were recruited for the study. The mean age of the antenatal clinic attendees was $28 \pm 2$ years, the mean gestational age at booking was 25 weeks and the mean parity was 2 . Fifteen (8.1\%) of the pregnant women were positive for Hepatitis B surface antigen. For the educational status of the pregnant women attending antenatal care $24(13 \%)$ had primary level of education, $122(66 \%)$ had secondary education, $33(17.8 \%)$ had tertiary education while $6(3.2 \%)$ had no formal education.

Table 1 Showing HBV infected pregnant women and NON-HBV infected pregnant women and their percentage frequency

\begin{tabular}{l|c|c|}
\hline \multicolumn{1}{c}{ Number } & Percentage frequency \\
\hline HBV & 15 & $8.1 \%$ \\
\hline NON-HBV & 170 & $91.9 \%$ \\
\hline
\end{tabular}

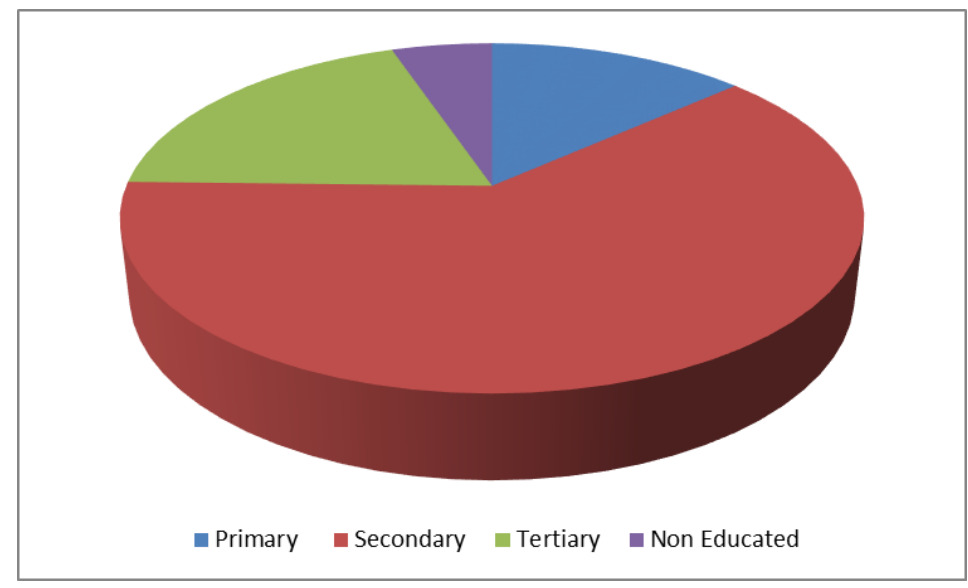

Figure 1 Distribution of educational status of ante natal clinic attendees

Primary - $24(13 \%)$

Secondary - 122 (66\%)

Tertiary - 33 (17.8\%) 
No formal education $-6(3.2 \%)$

Total $=185(100 \%)$

\section{Discussion}

The study showed the prevalence rate of HBV infection was $8.1 \%$ as illustrated in table 1 . This prevalence rate is higher than the global prevalence of 3.9\% and from other centers in Nigeria [2-5].There are myriad of factors for the high prevalence rate of HBV infection in rural communities as represented in Ogoni examples which include low immunization rate in rural areas as compared to urban and cosmopolitan cities [5-7]. Poor health awareness and education in vaccine preventable diseases in the hinterlands of Nigeria [7]. Lack of power and connection to internet network as compared to urban cities in Nigeria [7,8]. In addition, government and non-governmental organizations invest more on infection prevention and health awareness progammes in the urban cities compared to the rural areas [8]. Due to these reasons the populace in the urban areas are more conversant with the mode of transmission of HBV infections and other communicable diseases when compared rural communities [8-14].

Scholars have revealed that free screening by donor agencies for HBV infection is commoner in urban settings when compared to the rural area [2,3]. In these rural areas due to scarcity of resources testing for subjects were common among those who had clinical features of HBV infections [3,4]. as experienced by urban dwellers where routine screening is often carried out [2-4,7]. It could have been quite revealing if this study included screening of husbands whose wives tested positive for HBV infection [2,7-14].

\section{Conclusion}

The prevalence of HBV infection was 8.1\% in Ogoni southern Nigeria. This is worrisome, hence preventive measures for HBV infection implies that infection control measures should be stepped up in this community. Furthermore, HBV vaccines should be made available to the populace. In addition, improving vaccination coverage in both urban and rural settings in Nigeria and sub-Saharan Africa especially among infants and children, will reduce HBV new infection in these regions of the world. Collaboration involving local and international agencies like WHO, CDC, government and nongovernmental organizations is necessary to reduce the burden of HBV infections globally.

\section{Compliance with ethical standards}

\section{Acknowledgments}

Mother, Baby and Adolescent Care Global Foundation (Previously Mother and Baby Care Global Foundation).

\section{Disclosure of conflict of interest}

There was no conflict of interest

\section{Statement of informed consent}

Informed consent was obtained from all individual participants involved in this study.

\section{References}

[1] Musa et al. Prevalence of hepatitis B virus infection in Nigeria, 2000 - 2013. A meta-analysis. Niger J Clin Pract. 2015; 18(2): 163-72.

[2] Lim JK et al. Prevalence of Chronic Hepatitis B virus infection in the United States. American Journal of Gastroenterology. 2020; 155(9): 1429-1438.

[3] World Health Organization fact sheet, April. Hepatitis B. 2017.

[4] Eli et al. Human immunodeficiency virus and Hepatitis B virus coinfection Among Antenatal Clinic Attendees in Ogoni, south-south Nigeria. International Journal of Science and Research Development. 2021; 3(1): 37-39.

[5] Perz JF, Amstrong GL, Farrington LA. The contributions of hepatitis B virus and hepatitis C infections to cirrhosis and primary liver cancer worldwide. J Hepatol. 2006; 45: 529-538. 
[6] Ndububa DA, Ojo DS, Adetiloye VA. Chronic hepatitis in Nigerian patients: a study of 70 biopsy-proven cases. West Afr J Med. 2005; 24: 107-111.

[7] Sadoh AE, Eregie CO. Age at presentation for infant immunization in Nigeria: implications for hepatitis B immunization. Pub Health. 2008; 22: 1318-1320.

[8] Ola SO, Odaibo GN. Alfa-feto protein HCV and HCB infections in Nigerian patients with primary hepatcellular carcinoma. Niger Med Pract. 2007; 51: 33-35.

[9] Balogun TM, Durojaiye IO, Sajoe A. Seroepidemiology of hepatitis-B surface antigenaemia in HIV positive patients. West Ari J Med. 2010; 29: 169-73.

[10] Alao OE, Egwu C. Seroprevalence of hepatitis B surface antigen among prospective blood donors in an urban area of Benue State. Interact J Hematol. 2009; 5: 12.

[11] Lawal OA, Bakary AS, Uche LN. HBV infection among intending blood donors who incidentally tested positive to HIV antibody in two blood banks in Ibadan, Nigeria. World Appl Sci J. 2009; 87: 1269-1274.

[12] Ganem D, Prince AM. Hepatitis B virus infection: natural history and clinical consequences. N Engl J Med. 2004; 300: 1118-1129.

[13] Wilkins T, Zimmerman D, Schade RR. Hepatitis B: diagnosis and treatment. Am Fam Physician. 2010; 81: $965-$ 972.

[14] Knife F et al. Prevalence of Hepatitis B Virus Infection and Factors Associated with Hepatitis B Virus Infection Among Pregnant Women Presented to Antenatal Care Clinics at Adigut General Hospital in Ethiopia. International Journal of Womens' Health. 2021; 13: 119-127. 